\section{RevistadePolítica Económica y Desarrollo Sostenible}

Centro Internacional de Política Económica para el Desarrollo Sostenible
Revista de Política Económica y Desarrollo Sostenible

EISSN: 2215-4167 • Vol. 6 (1) • Julio-Diciembre, 2020: 1-24

DOI: https://doi.org/10.15359/peds.6-1.4

URL: http://www.revistas.una.ac.cr/politicaeconomica

Revista electrónica semestral publicada por el Centro Internacional de Política Económica para el Desarrollo Sostenible

Universidad Nacional, Lagunilla, Heredia Apartado 2393-3000

\title{
Objetivos e instrumentos de las políticas de innovación en Costa Rica ${ }^{1}$
}

\section{Objectives and Instruments of Innovation Policies in Costa Rica}

\author{
Jeffrey Orozco Barrantes ${ }^{2}$ \\ Sofía Guillén Pérez ${ }^{3}$ \\ sofgp@hotmail.com
}

Fecha de recibido: 28 de julio de 2020. Fecha de corregido: 10 de noviembre del 2020.

Fecha de publicación: 25 de noviembre del 2020

\begin{abstract}
Resumen
Con este estudio se pretende determinar el enfoque teórico desde el que se han diseñado las políticas e instrumentos propuestos por los principales entes públicos inmersos en el proceso de innovación en Costa Rica (MAG, MEIC, MICITT, Comex-Procomer, universidades públicas). Partimos de la identificación de los objetivos que a priori se han planteado estos actores públicos. ¿Cuál es la racionalidad que está detrás del diseño y aplicación de políticas para impulsar la innovación en el país? ¿Coinciden los objetivos planteados con los objetivos de fortalecer los componentes fundamentales de un Sistema Nacional de Innovación? Como lo plantean Kulman et al. (2010), es ideal que exista una adecuada coordinación entre la teoría para formular políticas de innovación y la práctica de las políticas mismas. Entre los resultados encontrados, destaca que algunos objetivos teóricos son contemplados por todos los actores públicos abordados (como proveer resultados en I+D y generar competencias a través del aprendizaje), mientras que otros objetivos se incorporan en menor dimensión (formar nuevos mercados, articular requerimientos de calidad e incubar empresas). Hay una pobre coordinación entre los diferentes actores.
\end{abstract}

Palabras clave: actores públicos, instrumentos, objetivos, política pública, sistema de innovación.

\begin{abstract}
This study aims to determine the theoretical approach from which the policies and instruments proposed by the main public entities immersed in the innovation process in Costa Rica (MAG, MEIC, MICITT, ComexProcomer, public universities) have been designed. We start from the identification of the objectives that these public actors have set in advance. What is the rationale behind the design and application of policies to promote innovation in the country? Do the objectives coincide with the objectives of strengthening the fundamental components of a National Innovation System? As stated by Kulman et al. (2010), it is ideal that
\end{abstract}

1 Este artículo respondió a una convocatoria sobre el tema "Pensamiento y práctica de la Política Económica", en el marco del 25 aniversario del CINPE-UNA

2 Economista. Doctor en Economía de la Innovación por la Universidad de Aalborg. Actualmente es profesor e investigador del CINPE-UNA

3 Economista por la Universidad de Costa Rica. Egresada de la Maestría Académica en Política Económica, UNA. Investigadora asistente, CINPE-UNA 
Revista de Política Económica y Desarrollo Sostenible • EISSN: 2215-4167

Vol. 6 (1) • Julio-Diciembre, 2020: 1-24

DOI: https://doi.org/10.15359/peds.6-1.4

Orozco Barrantes y Guillén Pérez

URL: http://www.revistas.una.ac.cr/politicaeconomica

there is an adequate coordination between the theory to formulate innovation policies and the practice of innovation. We found that some theoretical objectives are contemplated by all the public actors addressed (such as providing results in R\&D and generating competences through learning), while other objectives are incorporated in a smaller dimension (forming new markets, articulate quality requirements and incubate companies). But there is a poor coordination among the actors.

Key Words: public actors, tools, goals, public policy, innovation system.

\section{Introducción}

La innovación es un proceso creativo multicausal y variable, por lo que no es posible determinar una receta única e inflexible capaz de asegurar el éxito de un sistema nacional de innovación. Sin embargo, podemos indagar su naturaleza y potencial efectividad analizando la existencia de ciertos parámetros mínimos.

En este artículo analizamos la racionalidad de las políticas impulsadas por diferentes entes del sector público de Costa Rica. Partimos de un enfoque de sistemas de innovación y estudiamos los objetivos que se plantean los entes públicos, bajo el precepto de que los esfuerzos de planificación de los procesos de innovación en el ámbito público costarricense son planteados a través del cumplimiento de ciertos objetivos y metas establecidos desde los planes operativos de cada entidad.

Estudiamos si el diseño se plantea o no con una visión sistémica, o si cada entidad se traza objetivos de forma aislada, y analizamos la posibilidad de duplicación, superposición o ausencia de objetivos, tomando en consideración que, en Costa Rica, estos desgloses de metas cuantitativas o cualitativas forman parte de un cuerpo público-administrativo fragmentado, usualmente desarticulado y poco coordinado, que conduce a resultados deficientes en esta área (MICITT: 2017; OCDE, 2017; OCDE, 2018).

Se analiza entonces la coherencia en el diseño a priori de las políticas y medidas que impulsan los principales actores públicos inmersos en el Sistema Nacional de Innovación. ¿Coinciden los objetivos planteados con los objetivos de fortalecer los componentes fundamentales de un sistema de esta índole? ¿Cuál es la racionalidad que está detrás del diseño y aplicación de políticas para impulsar la innovación en el país? Partimos de la identificación de ciertas entidades medulares y analizamos sus objetivos en el sistema desde el enfoque de Edquist (2014). De esta forma, el resultado obtenido permite identificar las carencias de diseño del incipiente Sistema Nacional de Innovación de Costa Rica sugiriendo el fortalecimiento o la inclusión de objetivos hasta ahora débiles, o del todo ausentes.

\section{Marco teórico}

Entendemos la innovación como todo aquel proceso que implique nuevas creaciones de importancia económica (Edquist: 1997). La innovación es un concepto que ha evolucionado. 
De concebirse casi exclusivamente como ciencia y tecnología, pasó a incorporar elementos no tecnológicos y de creación de competencias y capacidades a partir de la óptica de la economía del aprendizaje (Lundvall: 2002a, pág. 224). Partimos de perspectivas holísticas considerando que la innovación es un proceso, determinado en cierto marco institucional, que comprende desde productos hasta organización, y en el cual la transferencia y creación de conocimiento y capacidades resulta determinante. La innovación es un proceso creativo multicausal influenciado por el marco institucional existente (las reglas del juego), los actores participantes (intereses y capacidades) y en función de cierto contexto cultural (costumbres, valores, creencias).

Se entiende como sistema al conjunto de componentes interrelacionados trabajando por un objetivo común (Carlsson et al., 2002, pág. 234), y por lo tanto, se comprende como sistema de innovación al conjunto de partes y aspectos de la estructura económica y del aparato institucional que afectan el aprendizaje y la investigación (Lundvall, 1992), debiendo entenderse la política de innovación como un elemento de coordinación estratégica entre la presión de transformarse, la habilidad de innovar y adaptarse al cambio, y los costos-beneficios de ese cambio con su respectiva distribución social y espacial (Lundvall, 2002b). De ahí que muchos autores propongan el estudio de los procesos de innovación desde enfoques de sistema (Lundvall, 1992, Nelson, 1993). El análisis integral de un sistema nacional de innovación trasciende la esfera económica o financiera y alcanza otros marcos institucionales, siendo necesariamente holístico y variante en tiempo y lugar. Chaminade y Edquist (2010) entienden las políticas de innovación como aquellas acciones públicas que incluyen los procesos de innovación, tanto para los procesos de desarrollo como de difusión, y que pueden estar orientadas tanto a objetivos económicos como no económicos.

Por lo general, no es posible determinar una receta única e inflexible capaz de asegurar el éxito de un sistema nacional de innovación, pero podemos indagar su naturaleza y potencial efectividad evaluando la existencia de ciertos parámetros mínimos de referencia general. Edquist (2014, pág. 191) establece 10 objetivos mínimos que un sistema de innovación debería desempeñar:

1. Proveer resultados de $\mathrm{I}+\mathrm{D}$, creando nuevo conocimiento.

2. Construir competencias (proveer educación y entrenamiento, crear capital humano, producir y reproducir habilidades, aprendizaje individual).

3. Formar nuevos mercados de productos.

4. Articular los requerimientos de calidad en la demanda de nuevos productos.

5. Crear las organizaciones y el cambio organizacional necesario para el desarrollo de nuevos campos de innovación (incentivar el espíritu empresarial para crear nuevas empresas y diversificar las firmas existentes creando nuevas organizaciones de investigación).

6. Facilitar redes de mercado y aprendizaje mediante mecanismos de mercado u otros, incluido el aprendizaje cooperativo entre diferentes organizaciones involucradas en el proceso de innovación. 
Revista de Política Económica y Desarrollo Sostenible • EISSN: 2215-4167

Vol. 6 (1) • Julio-Diciembre, 2020: 1-24

DOI: https://doi.org/10.15359/peds.6-1.4

Orozco Barrantes y Guillén Pérez

URL: http://www.revistas.una.ac.cr/politicaeconomica

7. Crear o modificar las instituciones o reglas del juego -leyes, impuestos, regulaciones, etc.- que influencian las organizaciones innovadoras y el proceso de innovación al proveer incentivos u obstáculos.

8. Impulsar actividades de incubación de empresas (proveer acceso a facilidades, soporte administrativo, etc., para nuevos esfuerzos de innovación).

9. Financiar los procesos de innovación y otras actividades que pueden facilitar el comercio del conocimiento y su adopción.

10. Proveer servicios de consultoría o apoyo como transferencia tecnológica, información comercial, apoyo legal, entre otros.

La racionalidad de las políticas de innovación se orienta a tratar de resolver los problemas del sistema, o sea, a tratar de resolver aquellas deficiencias que hacen que el sistema no pueda cumplir con esos objetivos fundamentales, incluyendo las fallas de mercado y por intervención. Los problemas del sistema para cumplir con esos objetivos, normalmente, se pueden entender como problemas de: provisión de infraestructura y de inversión; de transición; de lock-in; institucionales; de redes; de capacidades y aprendizaje; de desbalance exploración-explotación; o de complementariedad (Chaminade y Edquist, 2010). Borrás y Edquist (2013) sugieren una posible forma de agrupar las políticas e instrumentos para fomentar la innovación, considerando regulaciones (propiedad intelectual, normativa), transferencias económicas (fondos concursables, exoneraciones) e instrumentos suaves (alianzas, acuerdos). Orozco (2017) argumenta que, para aumentar la eficiencia de ese tipo de políticas e instrumentos, es importante considerar las especificidades geográficas, sectoriales o de tamaño de la empresa.

La ventaja que tiene el enfoque de sistemas de innovación es que da herramientas para detectar los problemas del sistema e identificar las mejores políticas para solucionar esos problemas, dando la posibilidad de combinar un enfoque sistémico para identificar fallas, con uno pragmático y experimental para diseñar políticas (Chaminade et al., 2009).

En lo que se ha generado consenso es que la innovación es un proceso creativo multicausal influenciado por el marco institucional existente (las reglas del juego), los actores participantes (intereses y capacidades) y en función de cierto contexto cultural (costumbres, valores, creencias). Así, el análisis integral de un sistema nacional de innovación trasciende la esfera económica o financiera y alcanza otros marcos institucionales; de ahí la necesidad de los enfoques de sistema (Lundvall, 1992, Nelson, 1993). Hay que considerar que para el diseño y aplicación de políticas de fomento de la innovación hay que tener también en cuenta esa lógica de sistema. Como lo plantean Kulman et al. (2010), es ideal que exista una adecuada coordinación entre la teoría para formular políticas en ese campo y la práctica de la innovación. En el rubro de las políticas innovativas, los autores plantean la necesidad de procesos interactivos para la búsqueda de opciones que incremente la eficiencia y eficacia de las políticas sobre los procesos innovadores. 
Revista de Política Económica y Desarrollo Sostenible • EISSN: 2215-4167

Vol. 6 (1) • Julio-Diciembre, 2020: 1-24

DOI: https://doi.org/10.15359/peds.6-1.4

Orozco Barrantes y Guillén Pérez

URL: http://www.revistas.una.ac.cr/politicaeconomica

\section{Marco metodológico}

Este enfoque metodológico centra su atención en la oferta y diseño de las políticas de innovación. No pretende abordar la demanda de esas políticas ni su aplicación efectiva, pero sí se plantea como un aspecto necesario en la agenda de investigación. Se aborda mediante una revisión bibliográfica exhaustiva de planes y memorias institucionales y entrevistas a profundidad de sujetos clave por entidad (estas se realizaron entre julio del 2019 y febrero del 2020).

En particular, el MICITT se analizó a través de la Memoria Institucional de mayo 2017abril 2018 y de entrevistas a las direcciones de I+D, Innovación y Apropiación Social del Conocimiento. Las universidades públicas (UCR, UNA, TEC, UNED, UTN) fueron abordadas desde sus planes operativos anuales (2019 UCR, 2019 UNA, 2018 TEC, 2018 UNED, 2017 UTN), y en el caso de las incubadoras y servicios afines, se entrevistó a gestores y encargados de AUGE, Innovaap, Proinnova, TEC Emprende, y del Centro de Incubación de Empresas de Base Tecnológica de la UTN, así como a la Oficina de Transferencia y Vinculación Externa de la UNA (encargada de la reactivación de la incubadora de esta universidad). La UNED no cuenta con incubadora. Procomer, el MAG y el MEIC fueron abordados mediante sus respectivos planes estratégicos 2015-2018 y a partir de entrevistas a la Digepyme del MEIC, el INTA y la Dirección Nacional de Extensión Agropecuaria del MAG, y la Dirección de Planificación estratégica y proyectos de Procomer.

Con lo anterior, se elabora una matriz de relación entre los objetivos contenidos en el plan de cada entidad y expresados por los informantes clave en contraposición con los objetivos mínimos recomendados por Edquist, los cuales se evalúan según la existencia o no de los instrumentos señalados por Orozco (2017) y Borrás y Edquist (2013), incorporando y adaptando instrumentos para Costa Rica. El desglose se muestra en la tabla 1, sobre posibles opciones de instrumentos que podrían existir y su clasificación por objetivo. La tabla 2 contenida en la sección de resultados muestra los instrumentos que efectivamente se aplican en el país.

La investigación está metodológicamente planteada en dos etapas. En la primera, cuyos resultados se exponen en este documento, la metodología se basa en comparar la oferta existente desde las principales entidades del sector público y académico con lo que dice la teoría de sistemas de innovación. La limitación en esta primera parte es que no se analiza la totalidad de entidades existentes, sino que se escogen las principales. La segunda parte del estudio, que se documentará en un artículo distinto, se basa en entrevistas a los beneficiarios de las políticas e instrumentos, determinando efectos positivos y vacíos en las políticas aplicadas. Se recomienda que en futuras investigaciones sea aborden los actores privados del Sistema Nacional de Innovación, ya que en este documento nos centramos exclusivamente en los actores públicos. 
Revista de Política Económica y Desarrollo Sostenible • EISSN: 2215-4167

Vol. 6 (1) • Julio-Diciembre, 2020: 1-24

DOI: https://doi.org/10.15359/peds.6-1.4

Orozco Barrantes y Guillén Pérez

URL: http://www.revistas.una.ac.cr/politicaeconomica

Tabla 1.

Instrumentos de políticas de innovación en Costa Rica según objetivos del sistema de innovación

\begin{tabular}{|c|c|}
\hline OBJETIVO & INSTRUMENTO DE POLÍTICA \\
\hline 1. Proveer $\mathrm{I}+\mathrm{D}$ & $\begin{array}{ll}\text { - } & \text { Ferias, premios o concursos de investigación } \\
\text { - } & \text { Programas, proyectos y departamentos de I+D }\end{array}$ \\
\hline 2. Construir competencias & $\begin{array}{l}\text { - Programas de educación formal (primaria, secundaria, universitaria, parau- } \\
\text { niversitaria, técnica) } \\
\text { - } \quad \text { Capacitaciones y talleres }\end{array}$ \\
\hline 3. Formar nuevos mercados & $\begin{array}{ll}\text { - } & \text { Compras públicas } \\
\text { - } \quad \text { Nuevos mercados internacionales o nacionales }\end{array}$ \\
\hline $\begin{array}{l}\text { 4. Articular requerimientos } \\
\text { de calidad }\end{array}$ & $\begin{array}{l}\text { - } \quad \begin{array}{l}\text { Articulación de requerimientos de calidad solicitados en ofertas públicas y } \\
\text { privadas. }\end{array} \\
\text { - } \quad \text { Seguimiento del proceso de obtención de certificados y otros requerimientos. }\end{array}$ \\
\hline $\begin{array}{l}\text { 5. Crear y modificar organi- } \\
\text { zaciones }\end{array}$ & $\begin{array}{ll}\text { - } & \text { Creación de nuevas empresas (por ejemplo, a través de incubadoras) } \\
\text { - } & \text { Creación de nuevas unidades de investigación } \\
\text { - } & \text { Diversificación de organizaciones actuales }\end{array}$ \\
\hline $\begin{array}{l}\text { 6. Facilitar redes de mercado } \\
\text { y aprendizaje }\end{array}$ & $\begin{array}{l}\text { - } \quad \text { Redes de mercado e información entre empresas, entidades públicas y ONG. } \\
\text { Incluye tanto el mercado nacional como el internacional. } \\
\text { - } \quad \text { Instrumentos que fomenten el aprendizaje interactivo entre diferentes orga- } \\
\text { nizaciones involucradas en los procesos de innovación. } \\
\text { - } \quad \text { Fomento de encadenamientos productivos }\end{array}$ \\
\hline $\begin{array}{l}\text { 7. Crear y modificar institu- } \\
\text { ciones (regulación) }\end{array}$ & $\begin{array}{l}\text { - } \quad \text { Consolidación de derechos de propiedad } \\
\text { - } \quad \text { Normativa interna de universidades y centros de investigación (naturaleza } \\
\text { estatutaria de las organizaciones y reglamentación laboral de los investiga- } \\
\text { dores). } \\
\text { - Normativa antimonopolio (política de promoción de la competencia) sobre } \\
\text { I+D y actividades innovadoras de las empresas. } \\
\text { - } \quad \text { Normativa ética relacionada con la innovación. } \\
\text { - } \quad \text { Normativa industrial de los efectos de la innovación. } \\
\text { - } \quad \text { Leyes fiscales. } \\
\text { - } \quad \text { Trámites públicos relacionados con la consolidación del sector productivo }\end{array}$ \\
\hline $\begin{array}{l}\text { 8. Impulsar actividades de in- } \\
\text { cubación }\end{array}$ & $\begin{array}{l}\text { - Acceso a instalaciones y apoyo administrativo de incubación para esfuerzos } \\
\text { innovadores }\end{array}$ \\
\hline $\begin{array}{l}\text { 9. Financiar procesos de in- } \\
\text { novación }\end{array}$ & $\begin{array}{ll}\text { - } & \text { Transferencia de fondos a universidades y centros de investigación } \\
\text { - } & \text { Fondos concursables } \\
\text { - } & \text { Exoneraciones y subsidios } \\
\text { - } & \text { Capital semilla y fondos a emprendedores(as) } \\
\text { - } & \text { Financiamiento de I+D }\end{array}$ \\
\hline $\begin{array}{l}\text { 10. Proveer servicios de con- } \\
\text { sultoría o apoyo }\end{array}$ & $\begin{array}{ll}\text { - } & \text { Transferencia de tecnología y conocimiento } \\
\text { - } & \text { Información comercial } \\
\text { - } \quad \text { Asesoría legal y/o financiera }\end{array}$ \\
\hline
\end{tabular}

Fuente: Adaptación propia con base en Edquist (2014), Orozco (2017) y Borrás y Edquist (2013). 
Revista de Política Económica y Desarrollo Sostenible • EISSN: 2215-4167

Vol. 6 (1) • Julio-Diciembre, 2020: 1-24

DOI: https://doi.org/10.15359/peds.6-1.4

Orozco Barrantes y Guillén Pérez

URL: http://www.revistas.una.ac.cr/politicaeconomica

\section{Resultados}

El presente trabajo no tiene por intención determinar los límites del Sistema Nacional de Innovación de Costa Rica, sino que concentra su atención en los actores ya definidos por el Ministerio de Ciencia, Tecnología y Telecomunicaciones de Costa Rica. En particular, la recopilación publicada por el MICITT (2007), Atlas para la innovación en Costa Rica, identifica los actores públicos que para estos efectos serán considerados los ejecutores de política de innovación y se analizarán según los parámetros de Edquist. La figura 1 desglosa los detalles.

Figura 1 .

Actores públicos relacionados con las etapas del proceso de innovación en Costa Rica

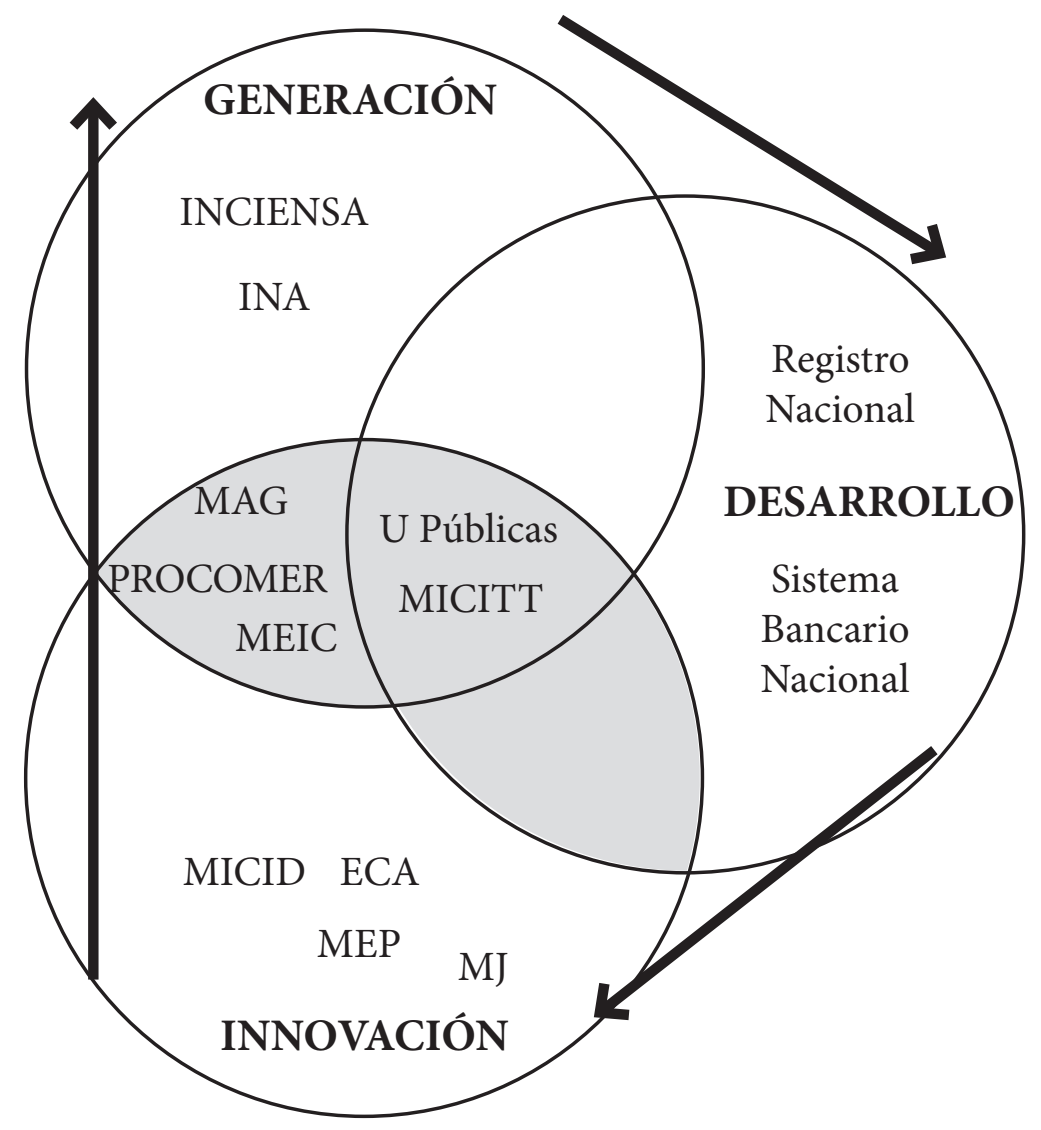

$\left.{ }^{*}\right)$ Siglas: Instituto Costarricense de Investigación y Enseñanza en Nutrición y Salud (INCIENSA), Instituto Nacional de Innovación de Transferencia en Tecnología (INTA), Instituto Nacional de Aprendizaje (INA), Ministerio de Agricultura y Ganadería (MAG), Ministerio de Economía, Industria y Comercio (MEIC), Ministerio de Comercio Exterior (Comex), Ministerio de Ciencia Tecnología y Telecomunicaciones (MICITT), Ministerio de Cultura, Juventud y Deportes (MCJD), Ente Costarricense de Acreditación (ECA), Ministerio de Educación Pública (MEP), Ministerio de Justicia y Paz (MJ).

Fuente: Elaboración propia basado en MICITT (2007). 
Revista de Política Económica y Desarrollo Sostenible • EISSN: 2215-4167

Vol. 6 (1) • Julio-Diciembre, 2020: 1-24

DOI: https://doi.org/10.15359/peds.6-1.4

Orozco Barrantes y Guillén Pérez

URL: http://www.revistas.una.ac.cr/politicaeconomica

Como se sugiere ampliamente en la literatura, los procesos de innovación no son lineales. Resultan de la interacción de diversos actores en etapas en cadena que conforman un ciclo no finito. MICITT (2007) determina tres etapas en este ciclo.

ETAPA 1: GENERACIÓN. Los conocimientos disponibles son contrastados por los agentes generadores (investigadores, expertos, personal técnico) con las necesidades y aspiraciones de la sociedad con el fin de generar ideas y proyectos que den lugar a nuevos bienes, servicios o procesos.

- ETAPA 2: DESARROLlO. Corresponde a la red de apoyo requerido para lograr convertir la oportunidad de innovación en una posible realidad de mercado. Incluye el apoyo especializado y el financiamiento.

- ETAPA 3: INNOVACIÓN. La innovación es puesta a disposición o no en el mercado. Su desempeño depende no solo de las características del mercado sino de la cultura y el marco institucional (reglas del juego).

En la figura 1 se observa que existen dos actores públicos partícipes de las tres etapas del ciclo en el Sistema Nacional de Innovación de Costa Rica: el MICITT y las universidades públicas. Ambas entidades apoyan el proceso de generación, desarrollo e innovación de una iniciativa. Existen otros tres actores participantes en más de una etapa: el MAG, el MEIC y el Comex (Procomer), quienes aportan servicios de apoyo en la primera y en la última fase. Así, el MAG, el MEIC, Comex-Procomer, el MICITT y las universidades públicas constituyen la médula del apoyo institucional público al sistema de innovación costarricense. Pero ¿qué coincidencias existen entre los objetivos de política de los actores públicos involucrados en el proceso de innovación en Costa Rica y los objetivos mínimos que un Sistema Nacional de Innovación debería desempeñar? ¿Cuál es la racionalidad que está detrás del diseño y aplicación de políticas para impulsar la innovación en el país?

Tal y como Edquist señala, difícilmente "seremos capaces de identificar todos los determinantes de la innovación debido a su complejidad; sin embargo, hay buenas razones para encaminar esfuerzos en esta dirección y desarrollar teorías entre variables específicas dentro del enfoque pragmático" (Edquist, 2014, pág. 190). Precisamente en un esfuerzo por desarrollar este enfoque pragmático, resulta significativo evaluar los objetivos que un sistema nacional de innovación tiene, confrontados ante los que debería tener. La evaluación del proceso de innovación debe abordarse desde la perspectiva sistémica con el fin de identificar los elementos a priori -sobrepuestos o no- que lo determinan.

\section{Ministerio de Ciencia, Tecnología y Telecomunicaciones (MICITT)}

En agosto de 1972 fue aprobada en la Asamblea Legislativa la Ley de Creación del Consejo Nacional para Investigaciones Científicas y Tecnológicas (CONICIT), en cuyo artículo 2 se proponen los cimientos del impulso a la innovación para fines pacíficos (Asamblea Legislativa: 
Revista de Política Económica y Desarrollo Sostenible • EISSN: 2215-4167

Vol. 6 (1) • Julio-Diciembre, 2020: 1-24

DOI: https://doi.org/10.15359/peds.6-1.4

Orozco Barrantes y Guillén Pérez

URL: http://www.revistas.una.ac.cr/politicaeconomica

1972, Ley $\mathrm{N}^{\circ}$ 5048, artículo 2). No obstante, a pesar de que la ley de creación del CONICIT fue elaborada con el propósito de promover la ciencia y la tecnología, el concepto "innovación para el desarrollo sostenido integral" no se incorporó en el marco jurídico costarricense sino hasta junio de 1990, en la Ley de Promoción del Desarrollo Científico y Tecnológico y Creación del MICITT, Ley $\mathrm{N}^{\circ} 7169$, en donde se establece como objetivo general "facilitar la investigación científica y la innovación tecnológica que conduzcan a un mayor avance económico y social en el marco de una estrategia de desarrollo sostenido integral, con el propósito de conservar, para las futuras generaciones, los recursos naturales del país y garantizarle al costarricense una mejor calidad de vida y bienestar, así como un mejor conocimiento de sí mismo y de la sociedad" (Asamblea Legislativa: 1990, Ley $\mathrm{N}^{\circ} 7169$, artículo 1). Se incorporó inclusive la necesidad de plantearse objetivos de largo plazo.

\section{Las universidades públicas (UCR, UNA, TEC, UNED, UTN)}

En la esfera del aprendizaje y la creación de conocimiento, las universidades públicas son actores determinantes que participan de las tres etapas esenciales del proceso innovador (generación-desarrollo-innovación). El ente máximo coordinador de estas universidades es el Consejo Nacional de Rectores (CONARE), creado en 1974.

Sus objetivos incluyen financiar la investigación y el desarrollo a través de sus investigadores(as) de planta y algunos enlaces de subcontratación, generar competencias a través del aprendizaje y facilitar redes entre estudiantes, docentes e investigadores (nacionales e internacionales). También establecen reglas (instituciones) necesarias para el desarrollo de la innovación y la $\mathrm{I}+\mathrm{D}$ en sus reglamentos y normativa interna, recomendando en ocasiones cambios de ley en el marco regulatorio del país. También existen diversos proyectos de incubación y acompañamiento a esfuerzos de innovación que se derivan de los acuerdos internos propios: AUGE-UCR (abierto), UNA Incuba (cerrado), UNA Emprendedores (cerrado), TEC Emprende Lab-CIETEC (abierto) y el CIEBT (Centro de Incubación de Empresas de Base Tecnológica) de la UTN (abierto solo a estudiantes de la UTN). En la UCR existen dos herramientas más de apoyo a la innovación: Proinnova e Innovaap (innovación pública).

Dada la particularidad de funcionamiento de estos instrumentos en las universidades públicas, nos detendremos a desglosar con mayor profundidad sus objetivos y funcionamiento.

Las incubadoras y programas vinculados no son estrictamente autónomos, pues se encuentran dentro del marco institucional de su respectiva universidad. Esto hace que algunas tengan mayor o menor flexibilidad según el avance normativo correspondiente y los recursos disponibles. La madurez organizativa de cada incubadora varía según estos elementos institucionales, de forma que no son estrictamente comparables entre sí y más bien deben ser entendidas como experiencias únicas que han encontrado soluciones propias a sus retos de planificación y ejecución. La planificación de las incubadoras es completamente diferente a la de los ministerios, ya que estos últimos son institucionalmente más rígidos. Así las incubadoras establecen los pasos a seguir de los emprendimientos que atienden, a partir de cierta metodología y, aunque planifican 
Revista de Política Económica y Desarrollo Sostenible • EISSN: 2215-4167

Vol. 6 (1) • Julio-Diciembre, 2020: 1-24

DOI: https://doi.org/10.15359/peds.6-1.4

Orozco Barrantes y Guillén Pérez

URL: http://www.revistas.una.ac.cr/politicaeconomica

metas y objetivos básicos, la mayoría de las tareas las resuelven en el proceso de ejecución (la incubadora con mayor desarrollo organizativo es AUGE, que fue galardonada en 2019 por el UBI Global World Benchmark Study como una de las veinte mejores incubadoras del mundo vinculadas a universidades). Finalmente, deben destacarse los casos de la Universidad Nacional en donde el programa UNA Incuba pausó su operación a partir del 2017 debido a modificaciones institucionales; al 2020, la Oficina de Transferencia y Vinculación Externa de la UNA se encuentra en proceso de reinventar y reactivar esta incubadora. Con respecto a la Universidad Estatal a Distancia, tiene procesos de extensión y vinculación académica pero no una incubadora formal.

La figura 2 detalla los hallazgos sobre los vínculos de las incubadoras de las universidades públicas. El espacio de encuentro de las tres incubadoras analizadas se da a través de CONARE, específicamente de su Comisión Nexo, en conjunto con la Red Impulsa, cuyo objetivo es fortalecer la vinculación universidad-empresa. En el marco de esta red se han elaborado talleres y concursos. Particularmente, la actividad "24 horas de innovación" es un espacio recurrente de encuentro para estas incubadoras y entes afines, como la Unidad de Gestión y Transferencia del Conocimiento para la Innovación (Proinnova) de la Universidad de Costa Rica.

El Sistema de Banca para el Desarrollo (SBD) constituye una banca de segundo piso que requiere de intermediarios para colocar los distintos fondos con los que cuenta. AUGE de la UCR dispone de un convenio ya en ejecución para la colocación de tres tipos de fondos: 1) De prototipado (para proyectos que solucionan problemas en la frontera de la innovación), 2) Puesta en marcha (para proyectos en la fase "Crear" de AUGE, con ventas dinámicas, innovadores y con no más de 3.5 años de facturar) y 3) De fortalecimiento (para proyectos en la fase "Escalar" de AUGE, con ventas dinámicas, innovadores, con registros contables y no más de 5 años de facturar). El Centro de Incubación de Empresas de Base Tecnológica de la UTN (CIEBT) estableció un convenio de colocación de fondos de forma que los recursos se encuentran disponibles a partir del año 2020 para prototipado y puesta en marcha. TEC Emprende no cuenta con convenio formal con el SBD. Para resolver los problemas de financiamiento de los proyectos que atiende, esta última incubadora recurre a alianzas estratégicas, particularmente a la establecida con AUGE, en donde TEC Emprende transfiere proyectos para que AUGE los vincule con fondos reembolsables o no reembolsables. Así, únicamente dos de las tres incubadoras cuentan con una alianza formal con el SBD.

TEC Emprende y AUGE han establecido convenios de colaboración con el MICITT a través de los fondos del Programa de Innovación y Capital Humano para la Competitividad -PINN-: el Mentor Day (AUGE). Para la UTN, el MICITT aportó financiamiento en las primeras seis ediciones del Programa de Formación Práctica en Innovación Orientada al Mercado (PIOM), del cual se gradúan gestores de innovación. Posteriormente, la UTN decidió seguirlo financiando en alianza con la Universidad de Leipzig. Los convenios entre MICITT-UTN no han sido propiamente con el CIEBT, sino con la universidad, por lo que se registra el vínculo como indirecto y temporal.

En lo que respecta a vínculos con Procomer como brazo del Ministerio de Comercio Exterior (Comex), las tres incubadoras han participado de convenios, alianzas y actividades formales 
para la internacionalización de proyectos (TEC Emprende), alianza con el programa Greentech de innovación verde (TEC Emprende y AUGE), el programa Seedstars para el entrenamiento empresarial y concursos de fomento a la innovación (CIEBT-UTN, AUGE), entre otros.

Las tres incubadoras forman parte de la Red Nacional de Incubadoras y Aceleradoras (RNIA), inscritas a través de la Digepyme del MEIC. Esta red tiene por propósito ser una plataforma digital unificada a la cual los emprendedores pueden acceder para encontrar el apoyo que requieren; sin embargo, aunque es formal lo registramos en la figura 2 como un vínculo débil o de hecho, pues la coordinación de acciones entre el MEIC y las incubadoras es más débil en algunos casos que en otros. En particular, AUGE posee fuertes vínculos formales con el MEIC, con quien coordina el Emprendetón (taller de emprendimiento).

En las entrevistas a profundidad, las representaciones de las incubadoras y del MAG no indican alianzas o convenios entre ellas y el Ministerio de Agricultura y Ganadería (MAG); por lo tanto, son vínculos débiles o no existen. Esto no significa que el MAG carezca de vínculos con las universidades públicas, sino que, en particular, las incubadoras universitarias parecen no estar focalizadas a emprendimientos del sector agropecuario.

Figura 2.

Vínculos de las incubadoras de las universidades públicas con algunos actores públicos del SIN

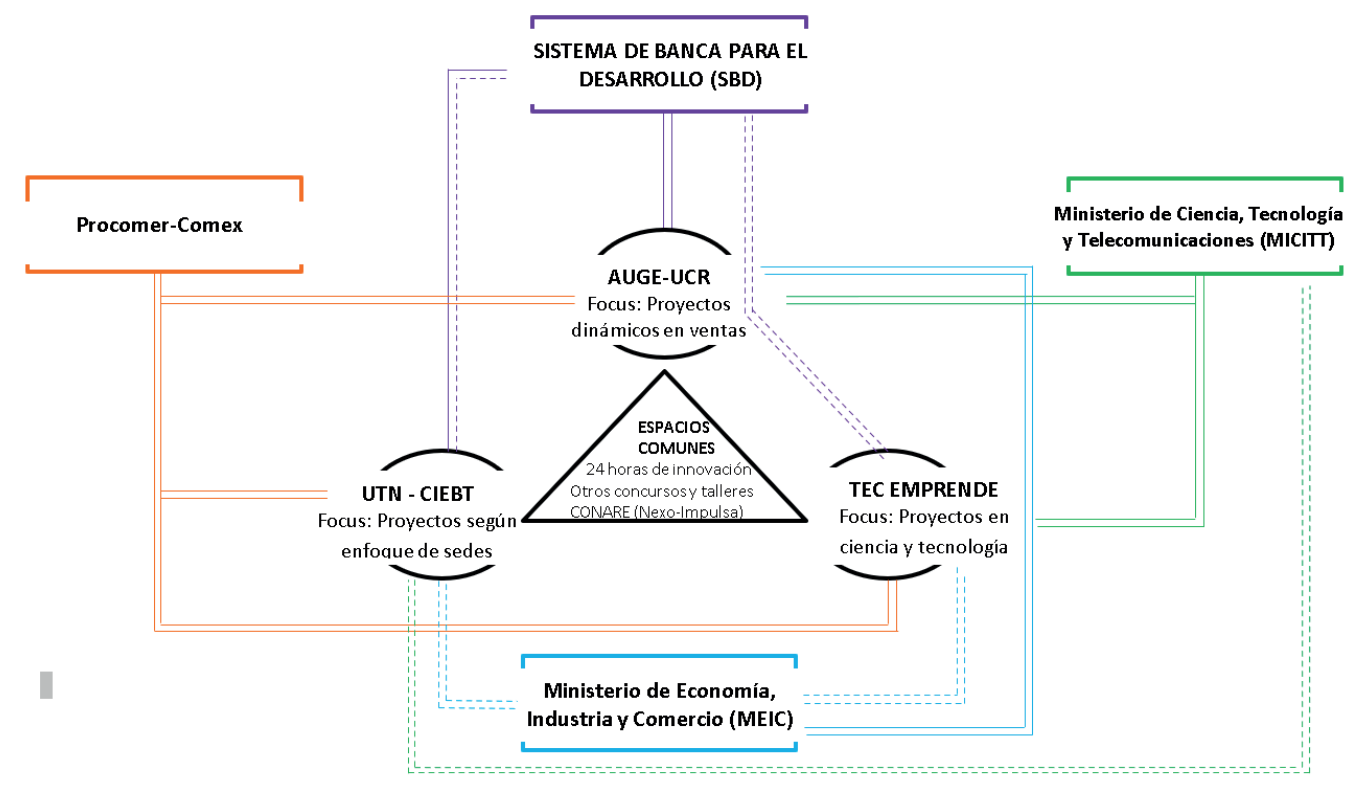

Fuente: Figura de elaboración propia a partir de resultados obtenidos. 
Revista de Política Económica y Desarrollo Sostenible • EISSN: 2215-4167

Vol. 6 (1) • Julio-Diciembre, 2020: 1-24

DOI: https://doi.org/10.15359/peds.6-1.4

Orozco Barrantes y Guillén Pérez

URL: http://www.revistas.una.ac.cr/politicaeconomica

\section{Ministerio de comercio exterior (Comex) y Promotora del Comercio Exterior de Costa Rica (Procomer)}

La Promotora del Comercio Exterior de Costa Rica es una entidad pública de carácter no estatal, creada en 1996 mediante la Ley No 7638, con el propósito de promover las exportaciones del territorio costarricense, mediante el apoyo al Ministerio de Comercio Exterior (Comex). Procomer contempla entre sus objetivos "diseñar y coordinar programas relativos a exportaciones e inversiones, con sujeción a las directrices que dicte el Poder Ejecutivo, y apoyar a la pyme exportadora y con potencial exportador" (Asamblea Legislativa: 1996, Ley $\mathrm{N}^{\circ}$ 7638, artículo 8). Define su plan estratégico en 3 ejes de acción: 1) Fortalecimiento institucional, 2) promoción del comercio exterior y 3) impulso a la competitividad del país (incluye promover la marca país y desarrollar encadenamientos, ecosistemas productivos y cadenas globales de valor).

\section{Ministerio de Economía, Industria y Comercio (MEIC)}

El MEIC fue creado mediante la Ley N 6054 en 1977 con los objetivos de: "1) Participar en la formulación de la política económica del Gobierno y en la planificación nacional, en los campos de su competencia y 2) ser el ente rector de las políticas públicas de Estado en materia de fomento a la iniciativa privada, desarrollo empresarial y fomento de la cultura empresarial para los sectores de industria, comercio y servicios, así como para el sector de las pequeñas y medianas empresas" (Asamblea Legislativa: 1977, Ley N 6054, artículo 1). El MEIC cuenta con una estructura especializada en pymes, llamada Dirección General de Apoyo de la Pequeña y Mediana Empresa (Digepyme), quien tiene a su cargo las áreas de comercialización, capacitación y asistencia técnica, financiamiento, información, desarrollo sostenible, innovación tecnológica y cooperación internacional.

\section{Ministerio de Agricultura y Ganadería (MAG)}

El Ministerio de Agricultura y Ganadería tiene, entre sus siete funciones establecidas en la Ley $\mathrm{N}^{\circ} 7064$ de 1987, la obligación de promover el desarrollo agropecuario a partir, fundamentalmente, de la investigación y de la extensión agrícola; así como coordinar con otros entes del sector agropecuario las acciones necesarias para el cumplimiento de sus objetivos. Su Plan Estratégico contempla tres objetivos: 1) Mejorar las capacidades competitivas de las PYMPAS y de la juventud rural, 2) fomentar y desarrollar la seguridad y soberanía alimentaria y nutricional del país, y 3) promover la articulación y coordinación interinstitucional de la gestión técnica y operativa del MAG (MAG, SENASA, SFE, INTA, Sistema Nacional para la Calidad [CONAC y ECA], sector público-privado $)^{4}$. Este último resulta de la mayor importancia en

4 Siglas: Servicio Nacional de Salud Animal (SENASA), Instituto Costarricense de Investigación y Enseñanza en Nutrición y Salud (INCIENSA), Instituto Nacional de Innovación de Transferencia en Tecnología (INTA), Ente Costarricense de Acreditación (ECA), Servicio Fitosanitario del Estado (SFE), Consejo Nacional para la Calidad (CONAC). 
Revista de Política Económica y Desarrollo Sostenible • EISSN: 2215-4167

Vol. 6 (1) • Julio-Diciembre, 2020: 1-24

DOI: https://doi.org/10.15359/peds.6-1.4

Orozco Barrantes y Guillén Pérez

URL: http://www.revistas.una.ac.cr/politicaeconomica

términos de vínculos para el sistema de investigación e innovación agropecuaria, pues fomenta la articulación y desarrollo de los sectores de granos básicos, hortalizas, raíces y tubérculos, frutales y ganadería. Igualmente, el MAG se propone concretar investigación y desarrollo desde diversos campos $(\mathrm{I}+\mathrm{D})$.

El resumen de los resultados se expone en la tabla 2.

Tabla 2.

Instrumentos contemplados por objetivo, según actor público ${ }^{5}$

\begin{tabular}{|c|c|c|c|c|c|}
\hline \multirow[b]{2}{*}{$\begin{array}{l}\text { OBJETIVO/ } \\
\text { FUNCIÓN }\end{array}$} & \multicolumn{5}{|c|}{ INSTRUMENTOS CONTEMPLADOS POR OBJETIVO DE POLÍTICA PÚBLICA SEGÚN ACTOR PÚBLICO } \\
\hline & MICITT & $\begin{array}{l}\text { UNIVERSIDA- } \\
\text { DES } \\
\text { PÚBLICAS }\end{array}$ & PROCOMER & MEIC & MAG \\
\hline $\begin{array}{l}\text { Proveer resul- } \\
\text { tados en } I+D\end{array}$ & $\begin{array}{l}\text { Ferias de Ciencia } \\
\text { y Tecnología; Pre- } \\
\text { mios Clodomiro } \\
\text { Picado Twight a la } \\
\text { investigación. }\end{array}$ & $\begin{array}{l}\text { Posgrados, uni- } \\
\text { dades de investi- } \\
\text { gación especia- } \\
\text { lizada y apoyos } \\
\text { varios a I+D. }\end{array}$ & $\begin{array}{l}\text { Impulso a I+D } \\
\text { en conjunto con } \\
\text { sector académico } \\
\text { nacional y sector } \\
\text { exportador. }\end{array}$ & $\begin{array}{l}\text { Elaboración y } \\
\text { divulgación de } \\
\text { investigación } \\
\text { especializada y es- } \\
\text { tudios de mercado } \\
\text { (medicamentos, } \\
\text { productos de la } \\
\text { canasta básica, } \\
\text { frijol, maíz, arroz, } \\
\text { sector lácteo, entre } \\
\text { otros). }\end{array}$ & $\begin{array}{l}\text { Investigación para: 1) Desa- } \\
\text { rrollo de sistemas productivos } \\
\text { sostenibles (Estrategia de } \\
\text { Fincas Integrales); 2) nuevas } \\
\text { formas de preparación de } \\
\text { alimentos con cultivos autóc- } \\
\text { tonos; 3) consumo de pro- } \\
\text { ductos sanos y nutritivos; y 4) } \\
\text { mejorar la competitividad de } \\
\text { productos sensibles (Programa } \\
\text { Nacional de Incremento de la } \\
\text { Productividad de los Produc- } \\
\text { tos Sensibles). Fortalecimiento } \\
\text { del SNITTA. }\end{array}$ \\
\hline $\begin{array}{l}\text { Generar com- } \\
\text { petencias a tra- } \\
\text { vés del apren- } \\
\text { dizaje }\end{array}$ & $\begin{array}{l}\text { Campamentos; } \\
\text { Olimpiadas; activi- } \\
\text { dades de divulga- } \\
\text { ción y capacitación } \\
\text { de CyT (Ruta In); } \\
\text { capacitación espe- } \\
\text { cializada de niñas } \\
\text { en las TIC; alfabeti- } \\
\text { zación digital de la } \\
\text { población a través } \\
\text { de CECI (en trans- } \\
\text { formación). }\end{array}$ & $\begin{array}{l}\text { Programas } \\
\text { de formación } \\
\text { (pregrado, gra- } \\
\text { do, posgrado y } \\
\text { cursos libres) y } \\
\text { capacitaciones a } \\
\text { externos. }\end{array}$ & $\begin{array}{l}\text { Capacitación, } \\
\text { desarrollo e inter- } \\
\text { nacionalización } \\
\text { de suplidores. } \\
\text { Entrenamiento } \\
\text { empresarial y } \\
\text { concursos en } \\
\text { Seedstars. }\end{array}$ & $\begin{array}{l}\text { Informar y capa- } \\
\text { citar a funciona- } \\
\text { rios públicos en } \\
\text { economía, indus- } \\
\text { tria y comercio. } \\
\text { Capacitaciones } \\
\text { y talleres a em- } \\
\text { prendedores(as). }\end{array}$ & $\begin{array}{l}\text { Capacitación para mejorar } \\
\text { gestión y desarrollo de em- } \\
\text { prendimientos agroproduc- } \\
\text { tivos sostenibles (Servicio } \\
\text { de Extensión Agropecuaria } \\
\text { dinámico y otros). }\end{array}$ \\
\hline
\end{tabular}

5 Siglas: Entiéndase SNITTA como Sistema Nacional Investigación y Transferencia Tecnología Agropecuaria; CECI es Centro Comunitario Inteligente; SINCYT = Sistema de Información Nacional en Ciencia y Tecnología; PITTAS = Programas de Investigación y Transferencia de Tecnología Agropecuaria; EMV = Enfoque de Mejoramiento de Vida; SBD = Sistemas de Banca para el Desarrollo. 
Revista de Política Económica y Desarrollo Sostenible • EISSN: 2215-4167

Vol. 6 (1) • Julio-Diciembre, 2020: 1-24

DOI: https://doi.org/10.15359/peds.6-1.4

Orozco Barrantes y Guillén Pérez

URL: http://www.revistas.una.ac.cr/politicaeconomica

\begin{tabular}{|c|c|c|c|c|c|}
\hline & MICITT & $\begin{array}{l}\text { UNIVERSIDA- } \\
\text { DES PÚBLICAS }\end{array}$ & PROCOMER & MEIC & MAG \\
\hline $\begin{array}{l}\text { Facilitación de } \\
\text { redes de apren- } \\
\text { dizaje y de } \\
\text { mercado }\end{array}$ & $\begin{array}{l}\text { Encuentros de } \\
\text { Mujeres en CyT; } \\
\text { festivales y ferias } \\
\text { (Prisma Innovation } \\
\text { Fest); plataformas } \\
\text { (Click para Innovar } \\
\text { y Portal Nacional de } \\
\text { Innovación); SIN- } \\
\text { CYT, Mentor Day. }\end{array}$ & $\begin{array}{l}\text { Cursos especiales } \\
\text { para actividades } \\
\text { de vinculación; } \\
\text { diversos instru- } \\
\text { mentos de divul- } \\
\text { gación, difusión } \\
\text { y transferencia } \\
\text { de conocimiento. }\end{array}$ & $\begin{array}{l}\text { Encuentros, alian- } \\
\text { zas y convenios } \\
\text { que faciliten redes } \\
\text { de mercado inter- } \\
\text { nacional a pymes } \\
\text { y a estructuras } \\
\text { Ex-Im; Mejorar } \\
\text { posicionamiento } \\
\text { de Esencial Costa } \\
\text { Rica. Plataforma } \\
\text { Blueprint. }\end{array}$ & $\begin{array}{l}\text { Apoyar la toma } \\
\text { de decisiones } \\
\text { con un sistema } \\
\text { integrado de } \\
\text { información. }\end{array}$ & $\begin{array}{l}\text { Fomento del acceso, uso y } \\
\text { control de recursos y ser- } \\
\text { vicios a organizaciones de } \\
\text { mujeres y jóvenes; sistema de } \\
\text { comercio internacional para } \\
\text { PYMPAS. }\end{array}$ \\
\hline $\begin{array}{l}\text { Formar nuevos } \\
\text { mercados }\end{array}$ & Sin instrumentos & $\begin{array}{l}\text { Desarrollo de } \\
\text { nuevos bienes y } \\
\text { servicios (a tra- } \\
\text { vés de la inves- } \\
\text { tigación y desa- } \\
\text { rrollo o de sus } \\
\text { incubadoras). }\end{array}$ & $\begin{array}{l}\text { Desarrollo de ben- } \\
\text { chmarks, alianzas } \\
\text { y convenios que } \\
\text { faciliten acceso de } \\
\text { pymes a los merca- } \\
\text { dos internacionales } \\
\text { y para estructuras } \\
\text { Ex-Im; impulso } \\
\text { a mecanismos } \\
\text { de promoción de } \\
\text { zona franca fuera } \\
\text { de GAM; amplia- } \\
\text { ción estratégica de } \\
\text { mercados. Proceso } \\
\text { Descubre. }\end{array}$ & Sin instrumentos & $\begin{array}{l}\text { Desarrollo de nuevas semi- } \\
\text { llas y variantes de especies. }\end{array}$ \\
\hline $\begin{array}{l}\text { Articulación } \\
\text { de requeri- } \\
\text { miento de cali- } \\
\text { dad en ByS }\end{array}$ & Sin instrumentos & Sin instrumentos & $\begin{array}{l}\text { Acompañamiento } \\
\text { en certificaciones } \\
\text { de calidad y de } \\
\text { certificaciones de } \\
\text { origen. Informa- } \\
\text { ción y capacita- } \\
\text { ción. Tramitología } \\
\text { en ventanilla } \\
\text { única de comercio } \\
\text { exterior (VUCE). }\end{array}$ & $\begin{array}{l}\text { Articulación vía } \\
\text { el Sistema Nacio- } \\
\text { nal para la Cali- } \\
\text { dad (SNC); sello } \\
\text { CO2 Neutral-Py- } \\
\text { me; mejores } \\
\text { prácticas en pro } \\
\text { de la calidad. }\end{array}$ & $\begin{array}{l}\text { Desarrollo y aplicación de } \\
\text { procedimientos y protocolos } \\
\text { de gestión de buenas prácti- } \\
\text { cas productivas, supervisio- } \\
\text { nes y certificaciones de CVO. }\end{array}$ \\
\hline $\begin{array}{l}\text { Incubación de } \\
\text { empresas }\end{array}$ & $\begin{array}{l}\text { No incuba. Enlaza } \\
\text { empresas para incu- } \\
\text { bar en el Programa } \\
\text { de Innovación Tec- } \\
\text { nológica (PIT) con } \\
\text { AUGE de la UCR. }\end{array}$ & $\begin{array}{l}\text { Acceso a insta- } \\
\text { laciones y apoyo } \\
\text { administrativo. } \\
\text { UCR: AUGE. } \\
\text { UTN: CIEBT. } \\
\text { TEC: CIE- } \\
\text { TEC-Emprende } \\
\text { Lab. La UNA } \\
\text { cerró UNA Incu- } \\
\text { ba y la UNED no } \\
\text { tiene. }\end{array}$ & $\begin{array}{l}\text { No incuba. Alian- } \\
\text { zas para conectar } \\
\text { innovación en } \\
\text { tecnologías ver- } \\
\text { des del programa } \\
\text { Greentech con } \\
\text { incubadoras. }\end{array}$ & $\begin{array}{l}\text { No incuba. } \\
\text { Consolidó la } \\
\text { Red Nacional } \\
\text { de Incubadoras } \\
\text { (RNIA) como } \\
\text { plataforma de } \\
\text { apoyo para em- } \\
\text { prendedores. }\end{array}$ & Sin instrumentos \\
\hline
\end{tabular}


Revista de Política Económica y Desarrollo Sostenible • EISSN: 2215-4167

Vol. 6 (1) • Julio-Diciembre, 2020: 1-24

DOI: https://doi.org/10.15359/peds.6-1.4

Orozco Barrantes y Guillén Pérez

URL: http://www.revistas.una.ac.cr/politicaeconomica

\begin{tabular}{|c|c|c|c|c|c|}
\hline & MICITT & $\begin{array}{l}\text { UNIVERSIDA- } \\
\text { DES PÚBLICAS }\end{array}$ & PROCOMER & MEIC & MAG \\
\hline $\begin{array}{l}\text { Financiamien- } \\
\text { to de procesos } \\
\text { de innovación }\end{array}$ & $\begin{array}{l}\text { Financiamiento no } \\
\text { reembolsable para } \\
\text { investigación y } \\
\text { proyectos en áreas } \\
\text { prioritarias a través } \\
\text { de Propyme y del } \\
\text { PINN (Programa de } \\
\text { Innovación). }\end{array}$ & $\begin{array}{l}\text { Financiamiento } \\
\text { directo a estu- } \\
\text { diantes e investi- } \\
\text { gadores internos, } \\
\text { con recursos } \\
\text { propios. Las incu- } \\
\text { badoras remiten } \\
\text { a fondos externos } \\
\text { (MEIC, MICITT } \\
\text { o SBD). }\end{array}$ & $\begin{array}{l}\text { Alianzas para } \\
\text { redirigir proyectos } \\
\text { de los programas } \\
\text { Greentech, Des- } \\
\text { cubre, Blueprint, } \\
\text { plataforma de cre- } \\
\text { cimiento verde y } \\
\text { capital de riesgo al } \\
\text { Sistema de Banca } \\
\text { para el Desarrollo, } \\
\text { fundaciones. }\end{array}$ & $\begin{array}{l}\text { Financiamiento } \\
\text { no reembolsable } \\
\text { a través de Di- } \\
\text { gepyme. }\end{array}$ & $\begin{array}{l}\text { Financiamiento no re- } \\
\text { embolsable (proyectos de } \\
\text { transferencia, programa de } \\
\text { inversión para organizacio- } \\
\text { nes de productores) y fondos } \\
\text { focalizados (fideicomisos } \\
\text { cafetalero y ganadero). }\end{array}$ \\
\hline $\begin{array}{lr}\text { Servicios } & \text { de } \\
\text { consultoría } & \text { o } \\
\text { apoyo } & \end{array}$ & $\begin{array}{l}\text { Información co- } \\
\text { mercial; asesoría } \\
\text { legal y financiera }\end{array}$ & $\begin{array}{l}\text { Extensión para } \\
\text { trabajar con co- } \\
\text { munidades, em- } \\
\text { presas y externos. } \\
\text { Transferencia de } \\
\text { conocimiento. } \\
\text { Incluye a Proin- } \\
\text { nova de la UCR y } \\
\text { al laboratorio de } \\
\text { innovación pú- } \\
\text { blica Innovaap, } \\
\text { también de la } \\
\text { UCR. }\end{array}$ & $\begin{array}{l}\text { Fidelización de } \\
\text { clientes, cartera de } \\
\text { servicios especia- } \\
\text { lizados por tipo de } \\
\text { cliente, desarrollo } \\
\text { de esquemas } \\
\text { tecnológicos } \\
\text { interoperables, } \\
\text { ofrecimiento de } \\
\text { servicios vir- } \\
\text { tuales-digitales, } \\
\text { inteligencia de } \\
\text { negocios, asesoría } \\
\text { y capacitación, } \\
\text { servicios especiali- } \\
\text { zados y enfocados } \\
\text { a pymes; revisión, } \\
\text { agilización y co- } \\
\text { municación de } \\
\text { requisitos para } \\
\text { comercio exterior. }\end{array}$ & $\begin{array}{l}\text { Asesoría en } \\
\text { medición de } \\
\text { procesos, apoyo } \\
\text { empresarial y } \\
\text { técnico. Gestión } \\
\text { en procesos de } \\
\text { formalización de } \\
\text { pymes. }\end{array}$ & $\begin{array}{l}\text { Transferencia tecnológica } \\
\text { (Programa Nacional de } \\
\text { Incremento de la Produc- } \\
\text { tividad de los Productos } \\
\text { Sensibles); asesoría en ser- } \\
\text { vicio integral de agricultura } \\
\text { familiar en sistemas produc- } \\
\text { tivos sostenibles; conjunto de } \\
\text { metodologías de trabajo para } \\
\text { lograr cambios conductuales } \\
\text { que promuevan la atención } \\
\text { de necesidades de vida en los } \\
\text { productores rurales (EMV); } \\
\text { Reactivación de los PITTAS }\end{array}$ \\
\hline $\begin{array}{l}\text { Creación y } \\
\text { cambio orga- } \\
\text { nizacional (ac- } \\
\text { tores) }\end{array}$ & $\begin{array}{l}\text { Creación de em- } \\
\text { presas y nuevas } \\
\text { unidades de inves- } \\
\text { tigación, PIT (con } \\
\text { AUGE-UCR). }\end{array}$ & $\begin{array}{l}\text { Creación de } \\
\text { empresas y nue- } \\
\text { vas unidades de } \\
\text { investigación. }\end{array}$ & $\begin{array}{l}\text { Establecimiento } \\
\text { de nuevas empre- } \\
\text { sas en zona franca } \\
\text { y de IED. }\end{array}$ & $\begin{array}{l}\text { Consolidación de } \\
\text { nuevas pymes. }\end{array}$ & $\begin{array}{l}\text { Creación y fortalecimiento } \\
\text { de organizaciones de produc- } \\
\text { tores (programa de gestión } \\
\text { empresarial y organizacional, } \\
\text { jóvenes y mujeres); fomentar } \\
\text { equipos institucionales. }\end{array}$ \\
\hline $\begin{array}{l}\text { Creación y mo- } \\
\text { dificación de } \\
\text { instituciones } \\
\text { (reglas) }\end{array}$ & $\begin{array}{l}\text { Representación ins- } \\
\text { titucional y planes } \\
\text { de trabajo; análisis } \\
\text { de proyectos de ley } \\
\text { y emisión de crite- } \\
\text { rios; normativa para } \\
\text { investigadores. }\end{array}$ & $\begin{array}{l}\text { Normativa inter- } \\
\text { na que incluye } \\
\text { la naturaleza de } \\
\text { los órganos de } \\
\text { investigación, la } \\
\text { reglamentación } \\
\text { laboral de los } \\
\text { investigadores y } \\
\text { las exigencias de } \\
\text { ética. }\end{array}$ & $\begin{array}{l}\text { Representación } \\
\text { institucional y } \\
\text { planes de trabajo; } \\
\text { alianzas y conve- } \\
\text { nios internacio- } \\
\text { nales. }\end{array}$ & $\begin{array}{l}\text { Normativa de } \\
\text { trámites que } \\
\text { inciden sobre el } \\
\text { sector producti- } \\
\text { vo; investigación } \\
\text { de denuncias } \\
\text { para la defensa } \\
\text { del consumidor y } \\
\text { promoción de la } \\
\text { competencia. }\end{array}$ & $\begin{array}{l}\text { Representación institu- } \\
\text { cional y planes de trabajo; } \\
\text { protección del patrimonio } \\
\text { agropecuario nacional de } \\
\text { plagas y enfermedades; EMV; } \\
\text { reconocimiento por buenas } \\
\text { prácticas agroambientales. }\end{array}$ \\
\hline
\end{tabular}

Fuente: Elaboración propia a partir de resultados obtenidos. 
Revista de Política Económica y Desarrollo Sostenible • EISSN: 2215-4167

Vol. 6 (1) • Julio-Diciembre, 2020: 1-24

DOI: https://doi.org/10.15359/peds.6-1.4

Orozco Barrantes y Guillén Pérez

URL: http://www.revistas.una.ac.cr/politicaeconomica

\section{Especificidades de los instrumentos planificados}

De los instrumentos contemplados por objetivo de cada entidad analizada, es posible identificar especificidades de interés (figura 3). En cuanto a instrumentos dirigidos a jóvenes (menores de 35 años), el MICITT implementa ferias, campamentos, olimpiadas, concursos y Ruta In. El MAG, a su vez, fomenta el acceso, uso y control de recursos y servicios a organizaciones de jóvenes rurales, incluyendo asesoría. El MEIC, por otro lado, en años anteriores ha incluido en sus objetivos instrumentos dirigidos a jóvenes como el Campamento de Emprendimiento 2017. En el caso de las incubadoras, debe destacarse que su objetivo no es la población joven como tal; sin embargo, en la práctica, ya que operan dentro de universidades públicas, la población atendida suele ser efectivamente joven en su mayoría.

Sobre instrumentos dirigidos a mujeres, el MEIC plantea el Programa de Empresariedad Femenina, el MICITT planifica desplegar instrumentos a partir de la Política Nacional para la Igualdad entre Mujeres y Hombres en la Formación, el Empleo y el Disfrute de los Productos de la Ciencia, Tecnología, las Telecomunicaciones y la Innovación 2018-2027, y el MAG fomenta el acceso, uso y control de recursos y servicios a organizaciones de mujeres rurales, incluyendo asesoría.

En la mayor cantidad de instrumentos, la especificidad corresponde a la ruralidad y la regionalización, pensados para aplicarse fuera del Valle Central urbano. A excepción de la incubadora TEC Emprende, los otros actores públicos analizados contemplan instrumentos explícitos de regionalización. El CIEBT de la UTN proporciona asesoría y acompañamiento en coordinación con un gestor de emprendimiento por sede (Atenas, Pacífico, Guanacaste, San Carlos y Central en Alajuela). AUGE ha establecido alianzas con las sedes de la Universidad de Costa Rica (Guanacaste, Caribe, Occidente y Pacífico) y en 2017 la agencia llevó su fase azul de acompañamiento hasta estos recintos. En general, las universidades públicas disponen de sedes a través de las cuales realizan investigación y desarrollo, formación, etc. El MAG opera desde sus múltiples agencias y se apoya en los proyectos de regionalización del INTA; sus aportes incluyen el diseño de nuevas semillas, la implementación de laboratorios vitrina con productores de zonas rurales, entre otros. Igualmente, el MEIC procura dar asesoría desde sus oficinas regionales en Limón, San Carlos, Pérez Zeledón, Liberia y Puntarenas. El MICITT ha procurado acercarse a las comunidades rurales y vulnerables a través de los CECI; sin embargo, ellos mismos reconocen la necesidad de reconfigurarlos, por lo que planifican reconvertirlos en laboratorios de innovación social). Esta entidad también desarrolla ferias, talleres y análisis de clúster para el proyecto de Promoción de la Innovación con Enfoque Regional. El Procomer trabaja en la promoción de zonas francas fuera de la GAM y ha elaborado iniciativas como Seedstars, que es un programa de entrenamiento para pymes ubicadas en las regiones Huetar Caribe, Huetar Norte, Chorotega, Brunca y Pacífico Central.

Sobre instrumentos para pymes (pequeñas y medianas empresas) o PYMPAS (pequeños y medianos productores agropecuarios), el MICITT dispone de los fondos no reembolsables Propyme, y el MEIC cuenta con las herramientas de asistencia de la Digepyme y otros departamentos 
Revista de Política Económica y Desarrollo Sostenible • EISSN: 2215-4167

Vol. 6 (1) • Julio-Diciembre, 2020: 1-24

DOI: https://doi.org/10.15359/peds.6-1.4

Orozco Barrantes y Guillén Pérez

URL: http://www.revistas.una.ac.cr/politicaeconomica

asociados. El MAG, por su naturaleza, concentra sus instrumentos en las PYMPAS y la innovación agropecuaria, incluyendo investigación y desarrollo. El Procomer cuenta con la plataforma de crecimiento verde para micro, pequeñas o medianas empresas. Plataforma de Crecimiento Verde opera en alianza para la obtención de fondos no reembolsables y tiene el propósito de generar transformaciones productivas en las empresas para alcanzar mayor competitividad en mercados internacionales con impacto ambiental. Las universidades públicas también trabajan esta área a través de la transferencia de conocimiento, la investigación y la extensión.

Hay también instrumentos con objetivos ligados a nuevos mercados de productos ambientales o desarrollados con el propósito de disminuir, adaptarse o mitigar los efectos del cambio climático. El Procomer cuenta con la Plataforma de Crecimiento Verde anteriormente señalada, pero también con Greentech, con instrumentos dirigidos a la creación de startups de tecnología verde. Por su parte, el MAG y el INTA trabajan en investigación y desarrollo de granos básicos con capacidad de mitigación y adaptación ante el cambio climático para luego ofrecerlos a los productores. El MEIC realiza informes sobre economía verde. También las universidades públicas planifican investigación en este campo.

Por otro lado, el laboratorio de innovación pública de la Universidad de Costa Rica, Innovaap, dirige sus instrumentos a la asesoría, acompañamiento y capacitación del sector público para migrar hacia la innovación organizativa y tecnológica. Destaca que el MEIC ha establecido alianzas con el propósito de fomentar la actividad emprendedora e innovadora de las personas adultas mayores. Particularmente con AGECO (Asociación Gerontológica Costarricense).

\section{Figura 3.}

Actores pùblicos que contemplan en sus objetivos espeficidades de instrumentos

Instrumentos de innovación dirigidos a jóvenes
InICITT, MAG, MEIC
MICITT, MAG, MEIC

Fuente: De elaboración propia. 
Revista de Política Económica y Desarrollo Sostenible • EISSN: 2215-4167

Vol. 6 (1) • Julio-Diciembre, 2020: 1-24

DOI: https://doi.org/10.15359/peds.6-1.4

Orozco Barrantes y Guillén Pérez

URL: http://www.revistas.una.ac.cr/politicaeconomica

De las entrevistas a profundidad realizadas (11), se identifica recurrencia en otros tres actores públicos con vínculos de importancia para los informantes clave: el Sistema de Banca para el Desarrollo (7 de 11), el Instituto Nacional de Aprendizaje (5 de los 11) y el INAMU (3 de 11).

\section{Percepciones sobre los desafíos}

Se desprende del análisis previo que, en suma, los distintos actores del sistema sí consideran la mayoría de los objetivos que sugiere Edquist (2014). Al preguntar a los informantes clave sobre los desafíos y obstáculos que perciben como probables causantes de incumplimiento de lo planificado, se evidencian muchas carencias efectivas del sistema. El gráfico 2 resume los hallazgos. Del total de los 11 informantes clave entrevistados, la mayoría identifica como limitación en el cumplimiento de los objetivos de la tabla 2 las práctica o normas propias de la institución (que van desde círculos de poder, cambios de jerarcas y normas inflexibles). Señalan que existen serias deficiencias de coordinación interinstitucional para ejecutar tareas planificadas (desfases temporales entre entidades y entendimiento heterogéneo del concepto de innovación). Señalan falta de recursos humanos, recursos financieros e infraestructura, siendo el primero el de mayor peso. A su vez, entidades como Procomer y las incubadoras universitarias puntualizan que las dinámicas propias de los sectores productivos a veces obstruyen el cumplimiento de ciertos objetivos (cambios en el mercado internacional y prácticas internas de las empresas). Finalmente, aparece la normativa y legislación nacional como posible obstáculo a enfrentar, en donde se subraya la necesidad de actualizar los conceptos y mecanismos para fomentar la innovación.

Gráfico 2.

Percepciones de desafíos en el cumplimiento de los instrumentos planificados (en cantidad de entrevistas)

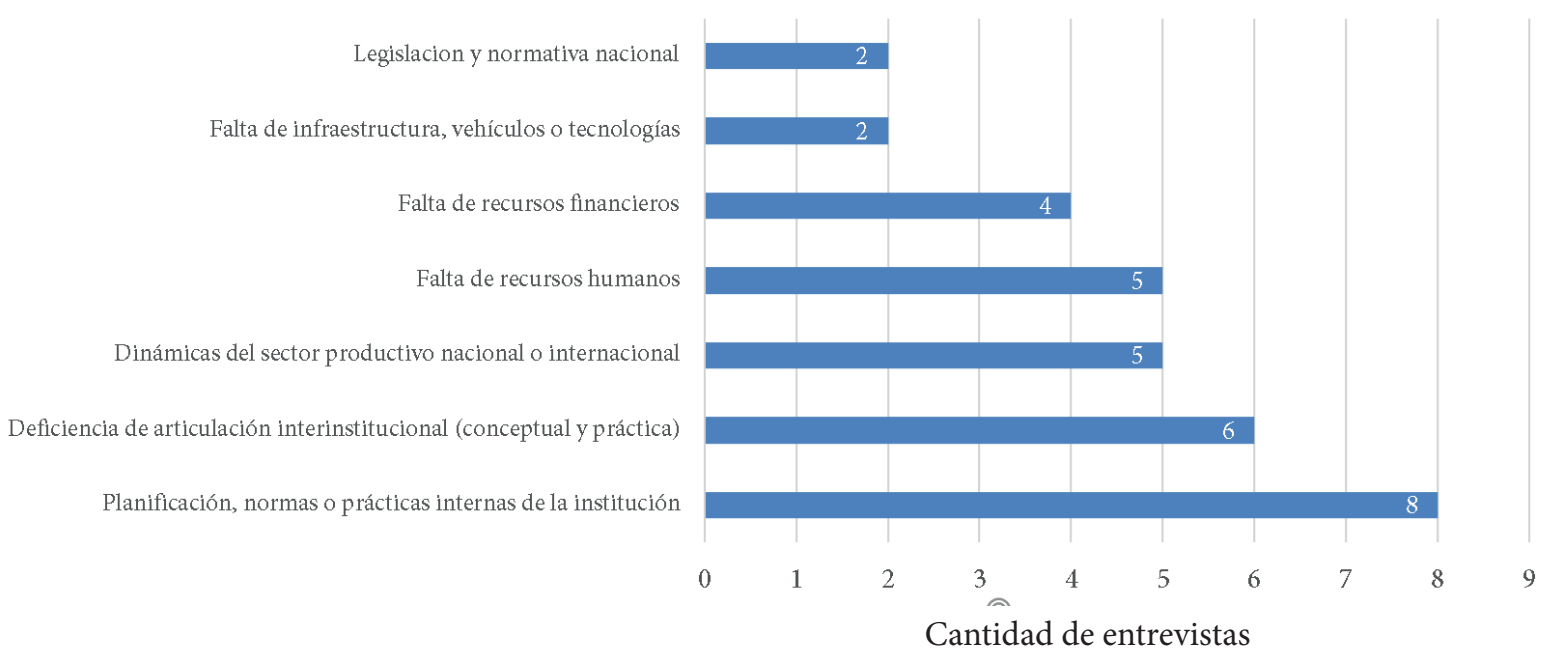

Fuente: Elaboración propia a partir de resultados obtenidos.

1/ Estos datos no provienen de una muestra estadísticamente representativa sino de las respuestas obtenidas, vía entrevista cualitativa, de 11 informantes clave de diferentes instituciones con puestos de alta responsabilidad. 
Revista de Política Económica y Desarrollo Sostenible • EISSN: 2215-4167

Vol. 6 (1) • Julio-Diciembre, 2020: 1-24

DOI: https://doi.org/10.15359/peds.6-1.4

Orozco Barrantes y Guillén Pérez

URL: http://www.revistas.una.ac.cr/politicaeconomica

\section{Conclusiones}

Las entidades estudiadas incluyen en su planificación la mayoría de los objetivos mínimos recomendados por Edquist (2014). Los dos objetivos planteados con mayor debilidad son el de "formar nuevos mercados" y "articular requerimientos de calidad en ByS". La mayoría de los actores públicos abordados parten de alianzas estratégicas con el sector público o privado para conseguir fondos reembolsables o no reembolsables que poner a disposición de los proyectos innovadores. En particular, destaca el papel del Sistema de Banca para el Desarrollo como banca de segundo piso que provee recursos para estos fines.

A pesar de los instrumentos planificados, los obstáculos que enfrentan estas instituciones sugieren la urgente necesidad de fortalecer el Sistema Nacional de Innovación en Costa Rica. Resalta que, aunque hay alguna coordinación entre los diferentes agentes, no hay un diseño más integral que permita la visualización del sistema como un todo y que dé cabida a estrategias y acciones concretas para fortalecer el sistema de forma global. Hace falta una entidad rectora con mayores capacidades para evaluar el sistema como un todo y diseñar políticas o estrategias de coordinación entre los entes involucrados.

Mapeamos acá los objetivos e instrumentos de los principales actores públicos involucrados en promover innovación. El siguiente paso es tomar la matriz de instrumentos aquí encontrada y evaluar los impactos en las poblaciones meta, para identificar opciones de mejora y mecanismos de creación de planes de trabajo institucionales más realistas y efectivos, resolviendo los obstáculos existentes.

En concreto, es importante atender una serie de limitaciones que fueron señaladas en el estudio de la OCDE (2017) y que también son evidentes en los resultados del presente estudio. En primer lugar, es necesario atender el problema de que el sistema de innovación costarricense es subdesarrollado, altamente fragmentado y sus actores tienen capacidades débiles para cumplir su función. Al respecto, recomendamos que se haga una inversión más estratégica en políticas e instrumentos de CTI, a partir de un esquema de planificación actualizado que permita tener un ente con visión estratégica, y una efectiva coordinación entre todos los actores involucrados. Plantear claramente los objetivos del desarrollo a seguir, y poner la reactivación como eje central, a partir del mejoramiento de la productividad de los sectores estratégicos. Hay que revisar detalladamente los esquemas de distribución de fondos para la innovación, propiciando estrategias con mayor cobertura e impactos medibles.

Un segundo aspecto a considerar, también señalado por OCDE (2017), es que la financiación de la investigación pública ha sufrido la falta de un enfoque unificado y no es sujeta a evaluaciones externas independientes nacionales hechas con regularidad. Sugerimos un nuevo esquema en el que se prioricen adecuadamente los objetivos a seguir y los proyectos a impulsar. Es recomendable pasar de un enfoque desde la oferta -como el que tienen actualmente las entidades estudiadas- a uno con visión sistémica. Universidades públicas, institutos públicos de 
investigación, cámaras empresariales, actores del sector salud y de distintos sectores estratégicos deben trabajar juntos en estrategias sectoriales para aportar soluciones concretas e innovadoras que permitan un mejor desempeño de los sectores productivos.

Hay que revisar también los mecanismos de gobernanza que no contribuyen a una adecuada articulación e implementación de políticas efectivas y las interacciones adecuadas requeridas en los sistemas de innovación nacional modernos.

Para mejorar la participación de las universidades e institutos públicos de investigación, sugerimos que se vaya generando un porcentaje mayor de los recursos del FEES que se dirijan a lograr objetivos del desarrollo, mejorando además los esquemas de propiedad intelectual, para que actores privados se vean incentivados a invertir en investigación y desarrollo generados en las universidades e institutos públicos de investigación. Las universidades públicas tienen el desafío de mejorar el impacto de sus programas de I+D y de emprendedurismo. Eso pasa por una mejor orientación de sus acciones a las necesidades del país y por un manejo más eficiente de los recursos disponibles, disminuyendo el costo de autoadministrarse.

Es importante rediseñar los esquemas de formación técnica para llenar de forma más adecuada las demandas de los sectores productivos. Y tomar medidas para evitar que el sistema financiero sea muy costoso o restrinja el acceso a recursos para invertir e impulsar la innovación. Los fondos específicos para emprendedurismo e innovación desde el MICITT y CONICITT van a ser muy insuficientes. Por eso hay que tomar medidas en el sistema financiero como un todo. Se requiere entender que el sistema financiero es una herramienta para el bienestar y una sana economía, y no un fin en sí mismo. El sistema financiero tiene que apuntarse en estos esquemas, y debe ser revisada la normativa que corresponda, para que lo regulado por la SUGEF y por otras entidades no siga siendo una piedra en el camino que imposibilita el acceso a los recursos. El Banco Central de Costa Rica (BCCR) tiene que contribuir también con inyección de liquidez, pero con mecanismos y reglas del juego novedosas.

El documento abre varias puertas de debate para futuras investigaciones. Desde determinar el cumplimiento efectivo de los objetivos del SłN contemplados por cada actor público analizado (ex post), hasta proponer líneas de acción de fortalecimiento de objetivos menos contemplados.

\section{Rereferencias bibliográficas}

Asamblea Legislativa de la República de Costa Rica (1972). Ley N 5048, Ley de Creación del Consejo Nacional para Investigaciones Científicas y Tecnológicas-Conicit. En Sistema Costarricense de Información Jurídica (SCIJ) de la Procuraduría General de la República. Consultar en: http://www.pgrweb.go.cr/scij/Busqueda/Normativa/Normas/nrm texto completo.aspx?param2=NRTC\&nValor $1=1 \&$ nValor2 $=1285 \&$ strTipM $=$ TC 
Revista de Política Económica y Desarrollo Sostenible • EISSN: 2215-4167

Vol. 6 (1) • Julio-Diciembre, 2020: 1-24

DOI: https://doi.org/10.15359/peds.6-1.4

Orozco Barrantes y Guillén Pérez

URL: http://www.revistas.una.ac.cr/politicaeconomica

Asamblea Legislativa de la República de Costa Rica (1990). Ley N 7169, Ley de Promoción del Desarrollo Científico y Tecnológico. En Sistema Costarricense de Información Jurídica (SCIJ) de la Procuraduría General de la República. Consultar en: http:// www.pgrweb.go.cr/scij/Busqueda/Normativa/Normas/nrm texto completo. aspx? param1=NRTC\&nValor1=1\&nValor2=11908\&nValor3=91174\&strTipM=TC

Asamblea Legislativa de la República de Costa Rica (1977). Ley $\mathrm{N}^{\circ}$ 6054, Ley Orgánica del Ministerio de Economía, Industria y Comercio. En Sistema Costarricense de Información Jurídica (SCIJ) de la Procuraduría General de la República. Consultar en: http://www.pgrweb.go.cr/scij/Busqueda/Normativa/Normas/nrm texto completo. aspx?param $1=$ NRTC\&nValor $1=1 \&$ nValor $2=48541 \&$ nValor $3=112940 \&$ strTipM $=$ TC

Asamblea Legislativa de la República de Costa Rica (1996). Ley Nº 7638, Crea Ministerio de Comercio Exterior y Promotora de Comercio Exterior. En Sistema Costarricense de Información Jurídica (SCIJ) de la Procuraduría General de la República. Consultar en: http://www.pgrweb.go.cr/scij/Busqueda/Normativa/Normas/nrm texto completo. aspx?param1=NRTC\&nValor1=1\&nValor2=25531\&nValor3=27012\&strTipM=TC

Asamblea Legislativa de la República de Costa Rica (2002). Ley $\mathrm{N}^{\circ}$ 8279, Sistema Nacional para la Calidad. En Sistema Costarricense de Información Jurídica (SCIJ) de la Procuraduría General de la República. Consultar en: http:// www.pgrweb.go.cr/scij/Busqueda/Normativa/Normas/nrm texto completo. aspx?param1=NRTC\&nValorl=1\&nValor $=48548 \&$ nValor $3=51738 \&$ strTipM=TC

Asamblea Legislativa de la República de Costa Rica (1987). Ley $\mathrm{N}^{\circ}$ 7064, Ley de Fomento a la Producción Agropecuaria FODEA y Orgánica del MAG. En Sistema Costarricense de Información Jurídica (SCIJ) de la Procuraduría General de la República. Consultar en: http://www.pgrweb.go.cr/scij/Busqueda/Normativa/Normas/nrm texto completo. aspx?param1=NRTC\&nValorl=1\&nValor2=546\&nValor3=90685\&strTipM=TC

Borrás, S. y Edquist, C. (2013). The Choice of Innovation Policy Instruments. Technological Forecasting \& Social Change 80 (2013) 1513-1522. Consultar en: https://www.sciencedirect. com/science/article/pii/S0040162513000504

Buitelaar, R.; Padilla, R. y Urrutia-Álvarez, R. (2000). Costa Rica: Sistema Nacional de Innovación. NU. CEPAL. División de Desarrollo Productivo y Empresarial. Serie 82. Consultar en: https://www.cepal.org/es/publicaciones/4454-costa-rica-sistema-nacional-innovacion

Carlsson et al. (2002). Innovation systems: analytical and methodological issues. Research Policy 31 (2002) 233-245.

CONARE (2017). Plan estratégico institucional 2017 - 2020. Consejo Nacional de Rectores. Aprobado en sesiones: 22-14 y 1-1. Consultar en: https://www.conare.ac.cr/conare/plan-estrategico 
Revista de Política Económica y Desarrollo Sostenible • EISSN: 2215-4167

Vol. 6 (1) • Julio-Diciembre, 2020: 1-24

DOI: https://doi.org/10.15359/peds.6-1.4

Orozco Barrantes y Guillén Pérez

URL: http://www.revistas.una.ac.cr/politicaeconomica

Crespi, g Y Monge, R (2018). El espejismo de la política de innovación en Costa Rica. Revista debates sobre innovación. Volumen 2, $\mathrm{N}^{\circ}$ 1. Universidad Autónoma Metropolitana, México.

Edquist, C. (2014). Systems of innovation: perspectives and challenges. Capítulo 7, contenido en el libro The Oxford Handbook of Innovation.

Edquist, C. (1997). Systems of Innovation Technologies, Institutions and Organizations. Editorial Pinter.

Johnson, B. (2016). The Learning Economy. In Lundvall, B. (author), The Learning Economy and the Economics of Hope (pp. 107-130). London; New York: Anthem Press. Recuperado de: http://www.jstor.org/stable/j.ctt1hj9zjd.10

Lundvall, B. et al. (2002a). National systems of production, innovation and competence building.. Research Policy 31 (2002) 213-231. Department of Business Studies, Aalborg University, Aalborg, Dinamarca.

Lundvall, B. (2002b). Innovation, Growth, and Social Cohesion: The Danish Model. Edward Elgar Publishing.

Lundvall, B. (2007). Innovation System Research: Where it came from and where it might go. En Globelics Working Papers Series. Working Paper No. 2007-01. Consultar en: http://www. globelics.org/article/innovation-system-research-where-it-came-from-and-where-it-might-go/

Lundvall, B. (1992). National Systems of Innovation: Toward a Theory of Innovation and Interactive Learning. Pinter Publishers.

Nelson, Richard R. (ed. 1993). National Innovation Systems. A Comparative Analysis. Nueva York: Oxford University Press.

MAG (2014). Plan Estratégico 2015-2018. Ministerio de Agricultura y Ganadería de Costa Rica. Unidad de Planificación Institucional. Consultar en: http://www.mag.go.cr/ bibliotecavirtual/e14-10870.pdf

MEIC (2014). Plan Estratégico Institucional 2015-2018. Ministerio de Economía, Industria y Comercio de Costa Rica. Consultar en: https://www.meic.go.cr/meic/documentos/ sr003mwsg/PEI\%20MEIC\%20r.pdf

MICITT (2007). Atlas para la innovación en Costa Rica. Informe final. Comisión Nacional para la Innovación 2007. Consultar en: https://www.micit.go.cr/images/innovacion/atlas para la innovacion en costa rica 2007.pdf

MICITT (2015). Plan Nacional de Ciencia, Tecnología e Innovación (PNCTI) 2015-2021. Consultar en: https://www.micit.go.cr/images/plan nacional cyt/pncti/pdf.pdf 
Revista de Política Económica y Desarrollo Sostenible • EISSN: 2215-4167

Vol. 6 (1) • Julio-Diciembre, 2020: 1-24

DOI: https://doi.org/10.15359/peds.6-1.4

Orozco Barrantes y Guillén Pérez

URL: http://www.revistas.una.ac.cr/politicaeconomica

MICITT (2017). Indicadores nacionales de ciencia, tecnología e innovación en Costa Rica 2016 2017. Consultar en: https://www.micit.go.cr/images/indicadores/2015-2016/pdf.pdf

MICITT (2017). Indicadores nacionales: ciencia, tecnología e innovación en Costa Rica 2015- 2016. Consultar en: https://vinv.ucr.ac.cr/sites/default/files/files/informe indicadores 2015-2016.pdf

MICITT (2018). Memoria institucional Mayo 2017-Abril 2018. Consultar en: https://www.micit. go.cr/images/memorias-institucionales/2017-2018/pdf.pdf

MICITT (2019). Estadísticas sector ciencia y tecnología. Consultar en: http://indicadores.micit. go.cr/dashboards/19855/actividades-id-en-empresas/

MIDEPLAN (2018). Informe de seguimiento de metas anuales 2018 y de cierre de período 2015-2018. Consultar en: https://documentos.mideplan.go.cr/share/s/HeSTOBOwRJWhoQgKy184jg

OCDE (2017). OECD Reviews of Innovation Policy: Costa Rica 2017, OECD Reviews of Innovation Policy, OECD Publishing, Paris. Consultar en: https://read.oecd-ilibrary.org/science-andtechnology/oecd-reviews-of-innovation-policy-costa-rica-2017/innovation-policy-andgovernance-in-costa-rica 9789264271654-8-en\#page1

OCDE (2018). Estudios económicos de la OCDE: Costa Rica 2018. Consultar en: https://www. oecd.org/eco/surveys/Costa-Rica-2018-Estudios-Economicos-de-la-OCDE.pdf

Orozco, J. et al. (2017). Politicas económicas para el desarrollo sostenible. GlobalSouth Press Inc. TM.

Procomer (2014). Plan Estratégico 2015-2018. Promotora de Comercio Exterior de Costa Rica. Consultar en: https://www.procomer.com/downloads/informes-planes/Plan estrategico PROCOMER 2015-2018.pdf

TEC (2017). Plan Anual Operativo 2018. Oficina de Planificación Institucional. Consultar en: https:// www.tec.ac.cr/sites/default/files/media/doc/plan anual operativo 2018 final cgr.pdf

UNED (2018). Plan Operativo Anual Institucional 2018. Universidad Estatal a Distancia de Costa Rica. Consultar en: https://www.uned.ac.cr/viplan/images/cppi/documentos/POA Institucional 2018.pdf

UCR (2017). Ampliación Plan Estratégico Institucional 2018-2020. Rectoría de la Universidad de Costa Rica. Consultar en: https://www.ucr.ac.cr/medios/documentos/2018/transparencia pei 2018-2020.pdf

UCR (2018). Plan Anual Operativo 2019. Rectoría, Oficina de Planificación Universitaria. Universidad de Costa Rica. Consultar en: https://www.ucr.ac.cr/medios/documentos/2019/ pao agregado 2019.pdf 
Revista de Política Económica y Desarrollo Sostenible • EISSN: 2215-4167

Vol. 6 (1) • Julio-Diciembre, 2020: 1-24

DOI: https://doi.org/10.15359/peds.6-1.4

Orozco Barrantes y Guillén Pérez

URL: http://www.revistas.una.ac.cr/politicaeconomica

UCR (2019). Estrategia de innovación y emprendimiento. Portal de la Investigación. Universidad de Costa Rica. Consultar en: https://vinv.ucr.ac.cr/estrategia-de-innovaciony-emprendimiento

UNA (2018). Plan Operativo Anual Institucional. POAI-2019. Universidad Nacional de Costa Rica. Consultar en: http://www.documentos.una.ac.cr/bitstream/handle/unadocs/9768/ POAI\%202019.pdf?sequence $=1$ \&is Allowed $=\mathrm{y}$

UTN (2017). Plan Operativo Anual Institucional 2017. Universidad Técnica Nacional. Consultar en: https://www.utn.ac.cr/sites/default/files/attachments/auditoria/Presupuesto\%20 UTN\%202017\%20\%28formato\%20CGR\%29 0.pdf 